\title{
FGF2 is crucial for the development of bovine luteal endothelial networks in vitro
}

\author{
Kathryn J Woad ${ }^{1}$, Amanda J Hammond ${ }^{1}$, Morag Hunter ${ }^{1}$, George E Mann ${ }^{1}$, Morag G Hunter ${ }^{1}$ \\ and Robert S Robinson ${ }^{2}$ \\ ${ }^{1}$ School of Biosciences and ${ }^{2}$ School of Veterinary Medicine and Science, University of Nottingham, \\ Sutton Bonington Campus, Loughborough, Leicestershire LE12 5RD, UK \\ Correspondence should be addressed to KJ Woad; Email: katie.woad@nottingham.ac.uk
}

\begin{abstract}
The development of the corpus luteum requires angiogenesis, and involves the complex interplay between factors such as vascular endothelial growth factor A (VEGFA), fibroblast growth factor 2 (FGF2) and platelet-derived growth factor (PDGF). However, the relative role of these factors remains to be elucidated. This study used a new physiologically relevant mixed luteal cell culture system to test the hypotheses that: a) FGF2 and VEGFA are critical for bovine luteal angiogenesis; and b) local luteal PDGF signalling stimulates the formation of endothelial networks. Cells were treated with receptor tyrosine kinase inhibitors against VEGFA (SU1498), FGF2 (SU5402) or PDGF (AG1295) activity. After 9 days in culture, endothelial cells were immunostained for von Willebrand factor (VWF) and quantified by image analysis. Highly organised intricate endothelial networks were formed in the presence of exogenous VEGFA and FGF2. The inhibition of FGF2 activity reduced the total area of VWF staining versus controls $(>95 \% ; P<0.001)$. Inhibition of VEGF and PDGF activity reduced the endothelial network formation by more than 60 and $75 \%$ respectively $(P<0.05)$. Progesterone production increased in all treatments from day 1 to $7(\boldsymbol{P}<\mathbf{0 . 0 0 1})$, and was unaffected by FGF2 or PDGF receptor kinase inhibition $(P>0.05)$, but was reduced by the VEGF receptor inhibitor on days 5 and $7(P<0.001)$. In conclusion, this study confirmed that VEGF signalling regulates both bovine luteal angiogenesis and progesterone production. However, FGF2 was crucial for luteal endothelial network formation. Also, for the first time, this study showed that local luteal PDGF activity regulates bovine luteal endothelial network formation in vitro.

Reproduction (2009) 138 581-588
\end{abstract}

\section{Introduction}

The growth and development of the corpus luteum $(\mathrm{CL})$ requires the establishment of a complex vascular system (Redmer \& Reynolds 1996, Reynolds \& Redmer 1998). This neovascularisation or angiogenesis is thought to be under the control of several factors, including vascular endothelial growth factor A (VEGFA; Ferrara et al. 2003), fibroblast growth factor 2 (FGF2; Presta et al. 2005) and platelet-derived growth factor (PDGF; Betsholtz 2004).

VEGFA has been shown to stimulate angiogenesis in the follicle and CL of many species. It is highly expressed in the bovine $\mathrm{CL}$ during the early luteal phase (Berisha et al. 2000) when extensive angiogenesis is occurring (Zheng et al. 1993). VEGFA acts via the tyrosine kinase receptors, VEGFR1 and VEGFR2; with VEGFR2 considered the principal signalling receptor (Ferrara et al. 2003). Both receptors have been localised to microvascular endothelial cells of the bovine CL (Gabler et al. 2004) with expression shown throughout the luteal phase (Berisha et al. 2000). The inhibition of VEGFA action in vivo with antibody or antagonist treatment against VEGFA or VEGFR2 in a number of species results in the profound inhibition of luteal function and angiogenesis, as evidenced by reductions in the number, size and vascularity of corpora lutea and resultant attenuated progesterone secretion (Zimmermann et al. 2001, Fraser et al. 2005, Yamashita et al. 2008).

FGF2 is mitogenic for CL-derived endothelial cells (Gospodarowicz et al. 1986) and luteal cells in culture (Grazul-Bilska et al. 1995), and stimulated progesterone secretion when infused into bovine corpora lutea (Liebermann et al. 1996). In the cow, FGF2 protein was specifically localised to endothelial cells and pericytes of the theca layer prior to the LH surge, but afterwards and in the collapsed follicle, FGF2 protein was found predominantly in the luteinising granulosa cell layer (Berisha et al. 2006). However, after a few days, FGF2 was absent from steroidogenic cells but re-appeared in endothelial cells (Berisha et al. 2006). We have recently shown that FGF2 protein levels are particularly high during the follicular-luteal transition, suggesting an important role for FGF2 during the development of the 
early bovine CL (Robinson et al. 2007). Furthermore, injections of FGF2 antibody directly into the bovine $\mathrm{CL}$ decreased luteal volume and progesterone production (Yamashita et al. 2008).

The PDGF family is composed of four polypeptide chains (PDGFA, PDGFB, PDGFC, PDGFD) which form five dimeric isoforms, with the most common being the homodimers PDGF-AA, PDGF-BB and the PDGF-AB heterodimer. The PDGFs exert their actions via tyrosine kinase receptors; PDGF-AA, PDGF-AB and PDGF-BB act via the PDGF receptor- $\alpha$ (PDGFRA), while PDGF-BB also binds to the PDGF receptor- $\beta$ (PDGFRB; Fredriksson et al. 2004).

PDGF isoforms and both PDGFRs have been localised to the ovary in several species. In the follicle, PDGFs are thought to influence the primordial-to-primary follicle transition (Nilsson et al. 2006), to stimulate cell proliferation (Shores \& Hunter 2000) and follicle development (Sleer \& Taylor 2007a), and influence steroidogenesis (Taylor 2000). In the rat ovary posthCG, the ligands PDGFA, PDGFB and PDGFC were localised to luteal steroidogenic cells. The PDGFRA was localised to theca-derived luteinising cells of the developing $\mathrm{CL}$, and with further development a subpopulation of luteal parenchymal cells and some vascular cells showed immunoreactivity for PDGFRA. By contrast, the PDGFRB was predominantly localised to cells of the luteal microvasculature (Sleer \& Taylor 2007b).

Perivascular cells such as pericytes that are closely associated with endothelial cells are important regulators of both the structure and function of vessels (Armulik et al. 2005). PDGFB is involved in attracting pericytes to new vessels during angiogenesis via activation of PDGFRB located on pericytes (Betsholtz 2004), and intraovarian PDGF-receptor blockade resulted in a reduction in the number of corpora lutea in the rat and mouse (Sleer \& Taylor 2007b, Kuhnert et al. 2008). Nevertheless, still very little is known about the role of PDGF in regulating luteal angiogenesis in general and there have been no studies in the cow.

We have recently developed a culture system that incorporates the multiple luteal cell types found in vivo (pericytes, fibroblasts, steroidogenic and endothelial cells; Robinson et al. 2008). These luteal cells in culture produce increasing concentrations of progesterone over time and respond to $\mathrm{LH}$ stimulation. Uniquely, this culture system also mimics luteal angiogenesis in vitro; supporting endothelial growth and proliferation, so that after 9 days in culture intricate networks of endothelial cells are formed and are stimulated by the addition of VEGFA and FGF2 (Robinson et al. 2008).

This study utilised this luteal cell culture system to investigate the roles of VEGFA, FGF2 and PDGF in luteal progesterone secretion and endothelial network formation by employing specific receptor tyrosine kinase inhibitors to the activity of each of the growth factors. The hypotheses tested in the present study are a) FGF2 and VEGFA are critical for bovine luteal angiogenesis; and b) local luteal PDGF signalling stimulates the formation of endothelial networks.

\section{Results \\ Formation of endothelial cell networks}

Extensive formation of endothelial cell networks was observed in the control wells after 9 days in culture. The von Willebrand factor (VWF)-positive cells had developed into tubule-like structures and had formed highly organised, intricate networks that superficially resembled a capillary bed (Fig. $1 \mathrm{~A}$ ).

The degree of endothelial cell network formation was greatly reduced following treatment with all three angiogenic inhibitors; however, some VWF staining was present in all treatments (Fig. 1B-D).

Quantification of the VWF staining revealed that angiogenic inhibitors reduced the number of endothelial clusters $(P<0.001$; Fig. 2A). The FGFR1 inhibitor SU5402 reduced the number of clusters by $94 \%$ versus controls $(P<0.001)$, with very few clusters present across the whole well. Both the VEGFR2 and PDGFR inhibitors, SU1498 and AG1295 respectively, resulted in lower numbers of endothelial networks compared to control wells $(P<0.05$ and $P<0.001$ respectively). Reductions were of a lesser extent than those following SU5402 treatment (Fig. 2A), with SU1498 and AG1295 treatment reducing cluster number by around 52 and $75 \%$ respectively.

The mean area of each endothelial cluster was affected by treatment overall ( $P=0.02$; Fig. $2 \mathrm{~B}$ ). While SU1498 and AG1295 had no effect on the mean size of individual endothelial clusters, inhibition of FGFR1 with SU5402 tended to reduce cluster size by $\sim 40 \%$ $(P=0.06$; Fig. 2B).

The total area of VWF staining was reduced by all angiogenic inhibitors $(P<0.001$; Fig. 2C). SU5402 showed the greatest inhibition of endothelial network formation, with a $>95 \%$ reduction in the total area of VWF staining compared with control wells $(P<0.001)$. Both SU1498 and AG1295 reduced total area of VWF staining by around 60 and $75 \%$ respectively $(P<0.05$ and $P<0.001$ respectively; Fig. 2C). While AG1295 consistently lowered VWF staining in each culture, the effects of SU1498 were more variable, with two cultures showing only a $25 \%$ reduction.

The total length of endothelial networks was reduced by angiogenic inhibitors $(P<0.001)$ in a similar manner to the total area of VWF staining (data not shown). SU5402 resulted in the greatest inhibition of endothelial network length, with a $>95 \%$ reduction in total network length versus control wells $(P<0.001)$. SU1498 and AG1295 treatment reduced endothelial network length 

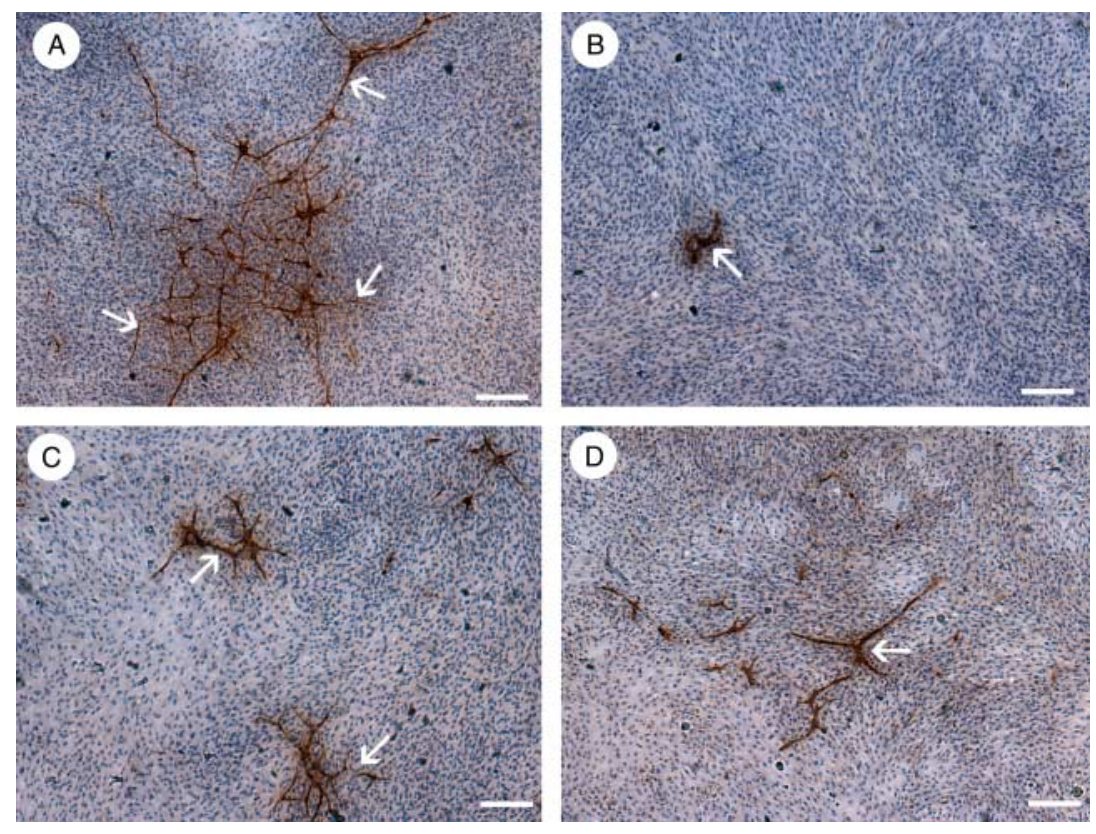

Figure 1 The effect of angiogenic inhibitors on the formation of endothelial cell networks from dispersed luteal cells in vitro. Representative images of cells treated with (A) control medium containing $1 \mathrm{ng} / \mathrm{ml}$ VEGFA and $1 \mathrm{ng} / \mathrm{ml} \mathrm{FGF2,}$ plus (B) $1 \mu \mathrm{M}$ SU5402 (FGFR1 inhibitor), (C) $2 \mu \mathrm{M}$ SU1498 (VEGFR2 inhibitor) or (D) $2 \mu \mathrm{M}$ AG1295 (PDGFR inhibitor). Endothelial cells were immunostained for von Willebrand factor (brown) after 9 days of culture. The arrows indicate the tubule-like structures and the scale bar represents $200 \mu \mathrm{m}$. by around 50 and $75 \%$ respectively $(P<0.05$ and $P<0.001$ respectively; data not shown). There was extensive cell proliferation in control and treated wells, with cells being confluent by 9 days.

\section{Production of progesterone}

Progesterone production increased eightfold from day 1 to 7 , with intermediate values on day $5(P<0.001$; Fig. 3$)$ across all treatments. There were no further increases in progesterone production on day 9 in the control wells. Treatment with the VEGFR2 inhibitor SU1498 resulted in an overall decrease in progesterone production versus controls $(P<0.001)$. Specifically, progesterone production was similar to control wells on days 1 and 3 , but was $\sim 25 \%$ lower on days 5 and $7 \quad(P<0.001)$ following SU1498 treatment. However, by day 9 , there were no differences when compared with control wells. By contrast, the production of progesterone in the presence of either AG1295 or SU5402 was not different from control wells at any time points ( $P>0.05$; Fig. 3$)$. There was no interaction between treatment and time $(P>0.15)$.

\section{Discussion}

Using a new in vitro model of luteal angiogenesis, the present study showed that the inhibition of receptors for the proangiogenic mediators FGF2, VEGFA or PDGF all resulted in reduced endothelial network formation. Treatment with SU5402, an FGF2 signalling inhibitor, dramatically reduced endothelial network formation by around $95 \%$ versus controls, as a result of reductions in both the number of endothelial clusters and mean area of each cluster. Significant reductions in the total area of VWF staining, and hence endothelial cell coverage, were also observed following treatment with SU1498 or AG1295 to block VEGFA and PDGF signalling respectively, although these reductions were less marked than following SU5402 treatment.

These results suggest that all three growth factors are active regulators of luteal angiogenesis. It also indicates that these factors must have complementary rather than redundant actions in luteal angiogenesis, since the absence of any one signal was sufficient to cause marked alterations in network formation, and the remaining factors were unable to compensate for the loss of any other factor. Studies of tumour angiogenesis have also shown that modulating FGF2 can inhibit the growth and vascularisation of xenografted tumours despite high levels of VEGFA (Czubayko et al. 1997).

Angiogenic regulators have been shown to act synergistically to stimulate angiogenesis. VEGFA and FGF2 in combination stimulate angiogenesis both in vivo and in vitro (Pepper et al. 1992, Asahara et al. 1995) and one underlying mechanism of co-stimulation is enhanced PDGFB-PDGFRB signalling (Kano et al. 2005). Indeed, the extent of the interplay between these factors may mean that target inhibition of one factor is almost equivalent to targeting the other(s).

Treatment with SU5402 resulted in the most dramatic reduction in endothelial clusters versus controls. Early studies suggested that FGF signalling is a key modulator of luteal angiogenesis, following the total inhibition of endothelial mitogenesis in response to ovine lutealconditioned media that had been immunoneutralised for FGF2 (Grazul-Bilska et al. 1992). We have recently shown that luteal FGF2 concentrations are highest during early luteal development, further suggesting that FGF2 is a key mediator of the initiation of angiogenesis 

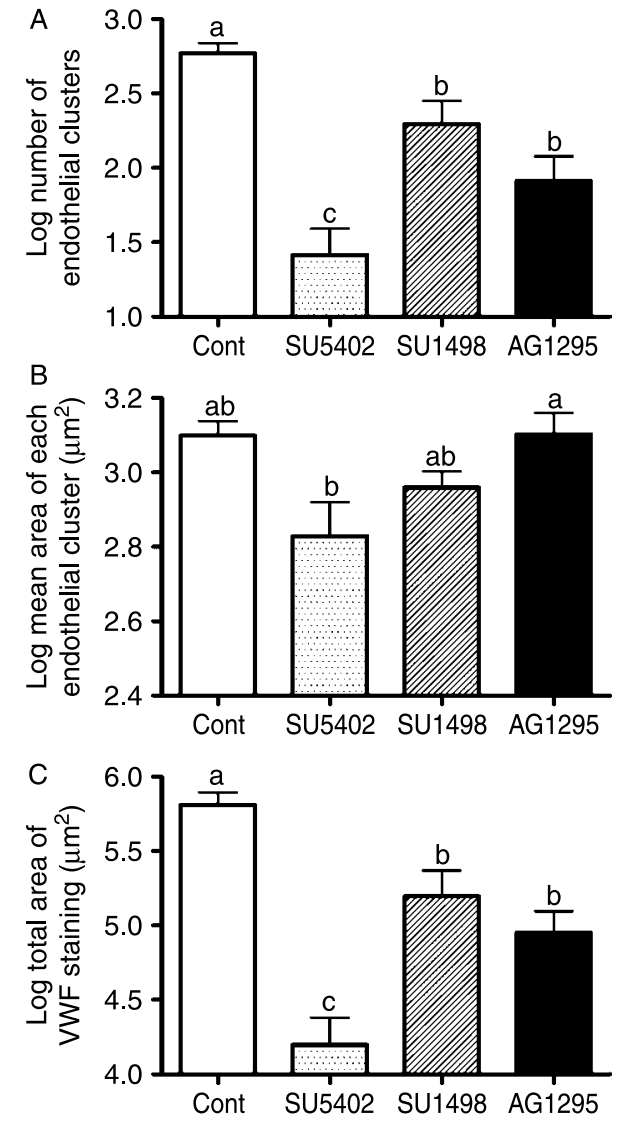

Figure 2 The effects of angiogenic inhibitors on luteal endothelial network development in vitro. Luteal cells were dispersed from early bovine $\mathrm{CL}$ ( $n=5$ cultures) and treated either with control medium containing $1 \mathrm{ng} / \mathrm{ml}$ VEGFA or $1 \mathrm{ng} / \mathrm{ml}$ FGF2 (Cont, open bars), plus $1 \mu \mathrm{M}$ SU5402 (FGFR1 inhibitor; dotted bars), $2 \mu \mathrm{M}$ SU1498 (VEGFR2 inhibitor; cross hatched lines) or $2 \mu \mathrm{M}$ AG1295 (PDGFR inhibitor; closed bars) for 9 days. Following image analysis and quantification of immunostaining for von Willebrand factor, the effects of inhibitors are shown on (A) mean number of endothelial clusters, (B) mean area of each endothelial cluster, and (C) total area of von Willebrand factor staining. For all three parameters, significant differences $(P<0.05)$ between treatment groups are indicated by different letters $a<b<c$, and the values are mean +S.E.M.

(Robinson et al. 2007) and in line with the observed reduction in network formation following SU5402 treatment. By contrast, others have shown that treatment to inhibit VEGFA bioactivity caused near absolute suppression of luteal angiogenesis in the rat, demonstrating that VEGFA is essential for neovascularisation (Ferrara et al. 1998). However, in our study inhibition of VEGFA only partially suppressed network formation and whether this may be due to species differences is currently unclear.

In the present study, the inhibition of PDGF signalling significantly reduced endothelial network formation in the absence of exogenous addition of ligand. AG1295 has been reported to completely prevent PDGF receptor autophosphorylation and DNA synthesis in response to PDGF stimulation, but exhibits

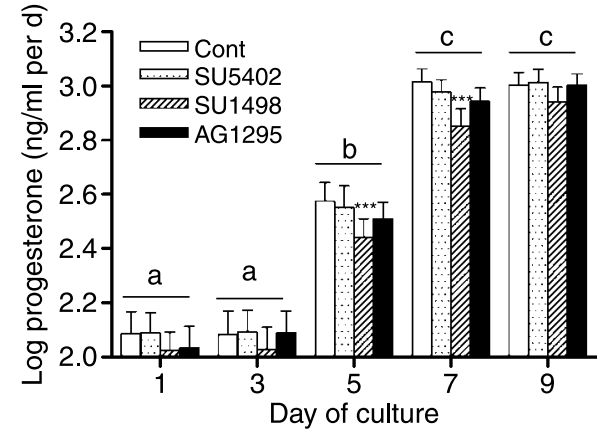

Figure 3 The effect of angiogenic inhibitors on the production of progesterone during culture in the in vitro luteal angiogenesis system. Dispersed luteal cells from early bovine CL ( $n=6$ cultures) were cultured for 9 days, with media collected and replaced on days 1, 3, 5, 7 and 9. The cells were treated with control medium containing $1 \mathrm{ng} / \mathrm{ml}$ VEGFA and $1 \mathrm{ng} / \mathrm{ml} \mathrm{FGF2} \mathrm{(Cont,} \mathrm{open} \mathrm{bars),} \mathrm{plus} 1 \mu \mathrm{M}$ SU5402 (FGFR1 inhibitor; dotted bars), $2 \mu \mathrm{M}$ SU1498 (VEGFR2 inhibitor; crossed-hatched lines) or $2 \mu \mathrm{M}$ AG1295 (PDGFR inhibitor; closed bars) for 9 days. There was a significant day $(P<0.001 ; \mathrm{a}<\mathrm{b}<\mathrm{c})$ and treatment effect $(P<0.001)$ with SU1498 decreasing progesterone production on days 5 and 7 (***P<0.001 versus CONT).

However, neither SU5402 nor AG1295 treatment had any effect on progesterone production. The data are mean +S.E.M.

only weak or negligible effects on the epidermal growth factor (EGF) receptor, insulin receptor, VEGF receptor or FGF receptor (Kovalenko et al. 1994). Given the specificity of PDGFR inhibition by AG1295 this suggests that PDGF is synthesised endogenously in our culture system. In support of this, PDGF ligands and PDGFRA were localised primarily to steroidogenic cells, while the PDGFRB was predominantly expressed by vascular cells in the rat CL (Sleer \& Taylor 2007b), suggesting that the PDGF system is able to play a paracrine role in the $\mathrm{CL}$.

Treatment with the tyrosine kinase inhibitors appeared to influence endothelial growth to differing degrees, with SU5402 showing the most marked reduction in total endothelial area. In addition, the nature of the inhibition seemed to differ, suggesting subtly different roles for each growth factor in modulating angiogenesis and luteal growth and development. FGF2, VEGFA and PDGF blockade all resulted in a reduction in the number of endothelial clusters formed in the luteal culture system. Following FGF2 inhibition there was a tendency for a reduction in the area of each cluster; a response that was not observed following VEGFA or PDGF inhibition. Furthermore, changes in endothelial networks in response to VEGFA inhibition were associated with significant reductions in progesterone production on days 5 and 7 of culture.

Alterations in the number of endothelial clusters might be the result of a reduction in an endothelial survival factor, as well as a block to proliferation. VEGFA not only stimulates proliferation of endothelial cells but it has also been shown to induce survival pathways (Gerber et al. 1998), including the expression of anti-apoptotic BCL2 
(Nor et al. 1999). Similarly, FGF2 acts as a survival factor by suppressing endothelial cell apoptosis (Karsan et al. 1997).

A survival role for PDGF has also been suggested in bone endothelial cells (Langley et al. 2004). PDGF can also enhance endothelial cell survival indirectly, via the induction of VEGFA expression in pericytes which then acts on endothelial cells (Reinmuth et al. 2001). However, since the luteal cultures were supplemented with exogenous VEGFA, it is unlikely that PDGF signalling is acting via this indirect route. Pericytes lie within the basement membrane and envelop microvessels, in contact with the underlying endothelium and are important modulators of vascular structure and function (Armulik et al. 2005). Their roles include providing a physical scaffold, guiding the proliferating tips of newly sprouting vessels, and communicating with and between endothelial cells (Bergers \& Song 2005). Previous experiments to block luteal PDGFRB signalling using an adenoviral approach induced luteal pericyte deficiency, with a reduction in pericyte coverage of $>90 \%$ (Kuhnert et al. 2008). Interestingly, the inhibition of luteal pericyte recruitment was accompanied by a $45 \%$ reduction in microvessel endothelial cell density (Kuhnert et al. 2008). The results of the current study suggest that pericyte activation through PDGFRB signalling is important in stimulating luteal angiogenesis, thus highlighting the considerable intercellular communication and interdependency that exits between endothelial cells and pericytes (Armulik et al. 2005).

Treatment with SU5402 to inhibit FGF2 signalling tended to reduce endothelial cluster size versus controls, whilst SU1498 and AG1295 treatment appeared intermediate, and overall there was an effect of treatment on mean endothelial cluster size $(P=0.02)$. The mean area of an endothelial cluster would likely be determined by coordinated actions on cell proliferation and migration. FGF2 and VEGFA are both known to be potent stimulators of endothelial cell mitogenesis and chemotaxis (Ferrara \& Davis-Smyth 1997, Presta et al. 2005). PDGF can also stimulate chemotaxis (Kundra et al. 1994) and the migration of pericytes ahead of endothelial cells is thought to guide endothelial sprouts (Bergers \& Song 2005).

The inhibition of VEGFA, FGF2 or PDGF action in vivo is associated with attenuated progesterone secretion resulting from changes in gross luteal structure, function and angiogenesis in the mouse, macaque and cow (Zimmermann et al. 2001, Fraser et al. 2005, Kuhnert et al. 2008, Yamashita et al. 2008). VEGFA and FGF2 stimulated progesterone release from microdialysed bovine early CL in vitro (Kobayashi et al. 2001). We have also shown previously that progesterone production was increased by the addition of FGF2 with VEGFA in the luteal angiogenesis culture system (Robinson et al. 2008). Similarly, the current study demonstrates that the inhibition of VEGFA signalling by luteal cells in vitro can also reduce progesterone production, albeit to a small degree.

In conclusion, this study demonstrated that FGF2, as well as VEGF, both play important roles in regulating bovine luteal endothelial network formation in vitro. Moreover, we showed that even in the presence of VEGFA, FGF2 was critical for the formation of luteal endothelial networks and this emphasises the importance of FGF2 in controlling luteal angiogenesis. Furthermore, we established for the first time that local PDGF signalling stimulates the formation of endothelial networks in vitro in the cow. The precise regulation of luteal angiogenesis is likely to involve a complex interplay between these factors.

\section{Materials and Methods}

All materials were purchased from Fisher Scientific, Loughborough, UK unless stated.

\section{Luteal angiogenesis culture system}

The effects of angiogenic inhibitors on the development of bovine luteal endothelial cell networks were investigated using a physiologically relevant luteal angiogenesis culture system as described by Robinson et al. (2008). Briefly, coverslips (circular, $19 \mathrm{~mm}$ diameter $\times 0.25 \mathrm{~mm}$ thick, SLS, Nottingham, UK) were placed in a 12-well plate and coated with $1 \mathrm{ml}$ of $10 \mu \mathrm{g} / \mathrm{ml}$ fibronectin (Sigma) for $4 \mathrm{~h}$, after which the fibronectin was removed and the wells were left to dry at $39{ }^{\circ} \mathrm{C}$ overnight. On the following day, the wells were rinsed with sterile distilled water, and then $1 \mathrm{ml}$ endothelial cell media (ECM) was added to each well. The ECM consists of a specialised endothelial cell medium (EBM-2; Lonza, Wokingham, UK) to which gentamycin, heparin, human EGF, $\mathrm{LR}^{3}$-insulin-like growth factor 1 , hydrocortisone and ascorbic acid were added as per the manufacturer's instruction. In addition, the medium was supplemented with $5 \mathrm{ng} / \mathrm{ml}$ LH (AFP11743B, biopotency $1.06 \times$ oLH NIDDK-I-2; a gift from Dr A F Parlow, NIDDK, CA, USA), 100 units $/ \mathrm{ml}$ penicillin, $10 \mu \mathrm{g} / \mathrm{ml}$ streptomycin, $10 \mu \mathrm{g} / \mathrm{ml}$ insulin, $5.5 \mu \mathrm{g} / \mathrm{ml}$ transferrin, $5 \mathrm{ng} / \mathrm{ml}$ selenium (all Sigma) and $2 \%(\mathrm{v} / \mathrm{v})$ fetal bovine serum (Lonza). Medium in all wells was further supplemented with $1 \mathrm{ng} / \mathrm{ml}$ VEGF and $1 \mathrm{ng} / \mathrm{ml}$ FGF2 (Lonza).

\section{Tissue collection and luteal angiogenesis culture system}

Bovine ovaries were collected from a local abattoir and transported to the laboratory in warmed $1 \times$ PBS. In all experiments, only early $\mathrm{CL}$ (day 1-4) were used and these were selected based on previously outlined criteria (Ireland et al. 1980). The CLs were removed connective tissue trimmed away and then sliced up using scissors. Luteal tissue was dispersed by incubation in M199 medium containing $2 \mathrm{mg} / \mathrm{ml}$ collagenase I type $1 \mathrm{~A}$ and $25 \mu \mathrm{g} / \mathrm{ml}$ DNase I (all Sigma) for $2 \times 45 \mathrm{~min}$ in a shaking water-bath at $37^{\circ} \mathrm{C}$. Cells (including luteal steroidogenic, endothelial, pericytes and fibroblasts) from 
each incubation were pooled together and then filtered through a $70 \mu \mathrm{m}$ cell strainer (BD Biosciences, Oxford, UK) and washed $3 \times$ in ECM. The cells were then plated out at $2 \times 10^{5}$ viable cells (as determined by trypan blue exclusion (Tennant 1964)) per well in a 12-well plate (total volume: $2 \mathrm{ml}$ ) and cultured at $39{ }^{\circ} \mathrm{C}$ in a humidified incubator in $5 \% \mathrm{CO}_{2} /$ $95 \%$ air. The medium was collected and replaced after 1, 3, 5 and 7 days of culture. On day 9, the medium was collected and the cells fixed in acetone:methanol $(1: 1)$ at $4{ }^{\circ} \mathrm{C}$ for $5 \mathrm{~min}$. The endothelial cells were then immunostained using VWF as an endothelial cell marker in order to assess network formation over time.

\section{Effect of angiogenic inhibitors on endothelial cell network formation and progesterone production}

The luteal cells were prepared from early corpora lutea (five cultures; one CL per culture) and plated as described above. The cells were then treated with control medium (containing $1 \mathrm{ng} / \mathrm{ml}$ VEGF and $1 \mathrm{ng} / \mathrm{ml}$ FGF2), or plus $1 \mu \mathrm{M}$ SU5402 $\left(\mathrm{IC}_{50}=10 \mu \mathrm{M}\right.$, specific FGFR1 inhibitor), $2 \mu \mathrm{M}$ SU1498 $\left(\mathrm{IC}_{50}=0.7 \mu \mathrm{M}\right.$, specific VEGFR2 inhibitor) or $2 \mu \mathrm{M}$ AG1295 tyrphostin $\left(\mathrm{IC}_{50}=0.5 \mu \mathrm{M}\right.$, specific PDGFRA and PDGFRB inhibitor). SU5402 interacts with the catalytic domain of the FGFR1 (Mohammadi et al. 1997) and has been used in numerous studies to specifically block FGF signalling and FGF2-induced angiogenesis (Numata et al. 2006, Nicoli et al. 2009). SU1498 inhibits tyrosine phosphorylation of VEGFR2, resulting in the suppression of endothelial cell proliferation in response to VEGF, and an inhibition of angiogenesis (Strawn et al. 1996, Katanasaka et al. 2008). Tyrphostin AG1295 has been reported to abolish autophosphorylation of the PDGF receptors and to block PDGF-stimulated DNA synthesis in endothelial cells (Kovalenko et al. 1994). All inhibitors were purchased from Calbiochem, Nottingham, UK and were initially dissolved in DMSO. The final concentration of DMSO in each treatment was $<0.1 \%$ $(\mathrm{v} / \mathrm{v})$. The control wells were treated with $0.1 \%(\mathrm{v} / \mathrm{v})$ DMSO. Each treatment was performed in triplicate with the cells being treated continuously for 9 days. The concentrations of angiogenic inhibitors used were based on $\mathrm{IC}_{50}$ values and previously reported concentrations (Banai et al. 1998, Kurimoto et al. 2004, Hatziapostolou et al. 2006, Sugiura et al. 2007, Wang et al. 2007). A further experiment was carried out to investigate the production of progesterone ( $n=6$ additional cultures). This was performed as described above with media being collected on days 1, 3, 5, 7 and 9 for progesterone analysis.

\section{Immunostaining of endothelial cells with VWF}

After fixation and each step, the cells were washed twice with $1 \times$ PBS for $5 \mathrm{~min}$ each wash. The first step was to block endogenous peroxidase activity with $3 \%(\mathrm{v} / \mathrm{v})$ hydrogen peroxide in methanol. Non-specific binding was blocked by incubating sections with $20 \%(\mathrm{v} / \mathrm{v})$ normal goat serum (NGS; Sigma) for $30 \mathrm{~min}$ and with no washing step, the cells were incubated with $4 \mu \mathrm{g} / \mathrm{ml}$ polyclonal rabbit anti-human VWF (Dako, High Wycombe, UK) in 2\% (v/v) NGS, as previously validated (Robinson et al. 2008). The slides were incubated in a humidified chamber at $4{ }^{\circ} \mathrm{C}$ overnight. On the following day, the primary antibody was detected using the Vectorstain $A B C$ method as per instructions (Vector Laboratories, Peterborough, UK) and visualisation was performed with diaminobenzidine (Vector Laboratories). The cells were counterstained with haematoxylin, dehydrated in graded IMS, then xylene. The coverslips were then removed from the well and mounted in distrene-plasticiser-xylene mountant.

\section{Quantification of VWF immunostaining by image analysis}

The quantification of VWF staining was performed as previously described (Robinson et al. 2008) with some minor modifications. All image analysis was performed using Image Pro-Plus 6.0 (Media Cybernetics, Wokingham, UK). The sections were visualised under a $5 \times$ objective lens and the area of brown (VWF) staining was highlighted. The highlighted area was then smoothed and any holes in the staining were removed. Only areas of VWF staining $>150 \mu \mathrm{m}^{2}$ and with tubule-like appearance were included in the analysis. The number and area of each cluster was recorded. The programme also determined the total area of VWF staining and total length of endothelial cell networks formed. This was repeated for a total of 20 fields of view across the whole well. Within each culture, 2 wells per treatment were randomly selected and analysed.

\section{Progesterone analysis}

The spent culture media was collected and stored at $-20^{\circ} \mathrm{C}$ for progesterone analysis. The progesterone concentration in media was determined using EIA (Ridgeway Science, St Briavels, Gloucestershire, UK) as previously validated (Picton et al. 1999). The samples were diluted 200-500-fold into $1 \times$ PBS as appropriate. All wells were analysed in duplicate. The intra-assay coefficient of variation (CV) was $8.3 \%$ and inter-assay $\mathrm{CV}$ at $4.3 \mathrm{ng} / \mathrm{ml}$ was $8.0 \%$.

\section{Statistical analyses}

All data were checked for normality and heterogeneity of variance and were log transformed where appropriate. The number of endothelial clusters, mean area of each cluster and total area and length of VWF staining were analysed by randomised block one-way ANOVA. The variables were blocked by culture, with treatment as the factor. If a significant difference $(P<0.05)$ was observed then Bonferroni's multiple comparison test was performed to elucidate where the differences lay. The production of progesterone was expressed as the concentration of progesterone in spent media per day. The production of progesterone was analysed by repeated measures ANOVA with day of culture as time factor and treatment as the factor. The data was blocked by culture. Bonferroni's multiple comparison test was performed on progesterone production on each day of culture to determine which treatments were different from the control. 


\section{Declaration of interest}

A declaration of interest statement reporting no conflict of interest has been inserted. Please confirm whether the statement is accurate.

\section{Funding}

The work was supported by the BBSRC grant BB/F002998.

\section{Acknowledgements}

We are grateful to the staff of Nottingham University for their assistance with sample collection and analysis.

\section{References}

Armulik A, Abramsson A \& Betsholtz C 2005 Endothelial/pericyte interactions. Circulation Research 97 512-523.

Asahara T, Bauters C, Zheng LP, Takeshita S, Bunting S, Ferrara N, Symes JF \& Isner JM 1995 Synergistic effect of vascular endothelial growth factor and basic fibroblast growth factor on angiogenesis in vivo. Circulation 92 365-371.

Banai S, Wolf Y, Golomb G, Pearle A, Waltenberger J, Fishbein I, Schneider A, Gazit A, Perez L, Huber R et al. 1998 PDGF-receptor tyrosine kinase blocker AG1295 selectively attenuates smooth muscle cell growth in vitro and reduces neointimal formation after balloon angioplasty in swine. Circulation 97 1960-1969.

Bergers G \& Song S 2005 The role of pericytes in blood-vessel formation and maintenance. Neuro-Oncology 7 452-464.

Berisha B, Schams D, Kosmann M, Amselgruber W \& Einspanier R 2000 Expression and tissue concentration of vascular endothelial growth factor, its receptors, and localization in the bovine corpus luteum during estrous cycle and pregnancy. Biology of Reproduction 63 1106-1114.

Berisha B, Steffl M, Amselgruber W \& Schams D 2006 Changes in fibroblast growth factor 2 and its receptors in bovine follicles before and after GnRH application and after ovulation. Reproduction 131 319-329.

Betsholtz C 2004 Insight into the physiological functions of PDGF through genetic studies in mice. Cytokine and Growth Factor Reviews 15 215-228.

Czubayko F, Liaudet-Coopman EDE, Aigner A, Tuveson AT, Berchem GJ \& Wellstein A 1997 A secreted FGF-binding protein can serve as the angiogenic switch in human cancer. Nature Medicine 3 1137-1140.

Ferrara N \& Davis-Smyth T 1997 The biology of vascular endothelial growth factor. Endocrine Reviews 18 4-25.

Ferrara N, Chen H, Davis-Smyth T, Gerber H-P, Nguyen T-N, Peers D, Chisholm V, Hillan KJ \& Schwall RH 1998 Vascular endothelial growth factor is essential for corpus luteum angiogenesis. Nature Medicine $4336-340$.

Ferrara N, Gerber H-P \& LeCouter J 2003 The biology of VEGF and its receptors. Nature Medicine 9 669-676.

Fraser HM, Wilson H, Morris KD, Swanston I \& Wiegand SJ 2005 Vascular endothelial growth factor trap suppresses ovarian function at all stages of the luteal phase in the macaque. Journal of Clinical Endocrinology and Metabolism 90 5811-5818.

Fredriksson L, Li H \& Eriksson U 2004 The PDGF family: four gene products form five dimeric isoforms. Cytokine and Growth Factor Reviews 15 197-204.

Gabler C, Plath-Gabler A, Killian GJ, Berisha B \& Schams D 2004 Expression pattern of fibroblast growth factor (FGF) and vascular endothelial growth factor (VEGF) system members in bovine corpus luteum endothelial cells during treatment with FGF-2, VEGF or oestradiol. Reproduction in Domestic Animals 39 321-327.

Gerber H-P, McMurtrey A, Kowalski J, Yan M, Keyt BA, Dixit V \& Ferrara N 1998 Vascular endothelial growth factor regulates endothelial cell survival through the phosphatidylinositol $3^{\prime}$-kinase/Akt signal transduction pathway. Requirement for Flk-1/KDR activation. Journal of Biological Chemistry 273 30336-30343.
Gospodarowicz D, Massoglia S, Cheng J \& Fujii DK 1986 Effect of fibroblast growth factor and lipoproteins on the proliferation of endothelial cells derived from bovine adrenal cortex, brain cortex, and corpus luteum capillaries. Journal of Cellular Physiology 127 121-136.

Grazul-Bilska AT, Redmer DA, Killilea SD, Kraft KC \& Reynolds LP 1992 Production of mitogenic factor(s) by ovine corpora lutea throughout the estrous cycle. Endocrinology 130 3625-3632.

Grazul-Bilska AT, Redmer DA, Jablonka-Shariff A, Biondini ME \& Reynolds LP 1995 Proliferation and progesterone production of ovine luteal cells from several stages of the estrous cycle: effects of fibroblast growth factors and luteinizing hormone. Canadian Journal of Physiology and Pharmacology 73 491-500.

Hatziapostolou M, Polytarchou C, Katsoris P, Courty J \& Papadimitriou E 2006 Heparin affin regulatory peptide/pleiotrophin mediates fibroblast growth factor 2 stimulatory effects on human prostate cancer cells. Journal of Biological Chemistry 281 32217-32226.

Ireland JJ, Murphee RL \& Coulson PB 1980 Accuracy of predicting stages of bovine estrous cycle by gross appearance of the corpus luteum. Journal of Dairy Science 63 155-160.

Kano MR, Morishita Y, Iwata C, Iwasaka S, Watabe T, Ouchi Y, Miyazono K \& Miyazawa K 2005 VEGF-A and FGF-2 synergistically promote neoangiogenesis through enhancement of endogenous PDGF-BPDGFR $\beta$ signaling. Journal of Cell Science 118 3759-3768.

Karsan A, Yee E, Poirier GG, Zhou P, Craig R \& Harlan JM 1997 Fibroblast growth factor-2 inhibits endothelial cell apoptosis by $\mathrm{Bcl}$-2-dependent and independent mechanisms. American Journal of Pathology 151 $1775-1784$.

Katanasaka Y, Ida T, Asai T, Maeda N \& Oku N 2008 Effective delivery of an angiogenesis inhibitor by neovessel-targeted liposomes. International Journal of Pharmaceutics 360 219-224.

Kobayashi S, Berisha B, Amselgruber WM, Schams D \& Miyamoto A 2001 Production and localisation of angiotensin II in the bovine early corpus luteum: a possible interaction with luteal angiogenic factors and prostaglandin $\mathrm{F}_{2 \alpha}$. Journal of Endocrinology 170 369-380.

Kovalenko M, Gazit A, Bohmer A, Rorsman C, Ronnstrand L, Heldin C-H, Waltenberger J, Bohmer F-D \& Levitzki A 1994 Selective plateletderived growth factor receptor kinase blockers reverse sistransformation. Cancer Research 54 6106-6114.

Kuhnert F, Tam BYY, Sennino B, Gray JT, Yuan J, Jocson A, Nayak NR, Mulligan RC, McDonald DM \& Kuo CJ 2008 Soluble receptor-mediated selective inhibition of VEGFR and PDGFR beta signaling during physiologic and tumor angiogenesis. PNAS 105 10185-10190.

Kundra V, Escobedo JA, Kazlauskas A, Kim HK, Rhee SG, Williams LT \& Zetter BR 1994 Regulation of chemotaxis by the platelet-derived growth factor receptor-(beta). Nature 367 474-476.

Kurimoto N, Nan Y-S, Chen Z-Y, Feng G-G, Komatsu T, Kandatsu N, Ko J, Kawai N \& Ishikawa N 2004 Effects of specific signal transduction inhibitors on increased permeability across rat endothelial monolayers induced by neuropeptide Y or VEGF. American Journal of Physiology. Heart and Circulatory Physiology $287 \mathrm{H} 100-\mathrm{H} 106$.

Langley RR, Fan D, Tsan RZ, Rebhun R, He J, Kim S-J \& Fidler IJ 2004 Activation of the platelet-derived growth factor-receptor enhances survival of murine bone endothelial cells. Cancer Research 64 $3727-3730$.

Liebermann J, Schams D \& Miyamoto A 1996 Effects of local growth factors on the secretory function of bovine corpus luteum during the oestrous cycle and pregnancy in vitro. Reproduction, Fertility, and Development 8 1003-1011.

Mohammadi M, McMahon G, Sun I, Tang C, Hirth P, Yeh BK, Hubbard SR \& Schlessinger J 1997 Structures of the tyrosine kinase domain of fibroblast growth factor receptor in complex with inhibitors. Science 276 955-960.

Nicoli S, De Sena G \& Presta M 2009 Fibroblast growth factor 2-induced angiogenesis in zebrafish: the zebrafish yolk membrane (ZFYM) angiogenesis assay. Journal of Cellular and Molecular Medicine [in press]. DOI: 10.1111/j.1582-4934.2008.00432.x

Nilsson EE, Detzel C \& Skinner MK 2006 Platelet-derived growth factor modulates the primordial to primary follicle transition. Reproduction 131 1007-1015.

Nor JE, Christensen J, Mooney DJ \& Polverini PJ 1999 Vascular endothelial growth factor (VEGF)-mediated angiogenesis is associated with enhanced endothelial cell survival and induction of $\mathrm{Bcl}-2$ expression. American Journal of Pathology 154 375-384. 
Numata $\mathrm{Y}$, Terui T, Okuyama R, Hirasawa N, Sugiura $\mathrm{Y}$, Miyoshi I, Watanabe T, Kuramasu A, Tagami H \& Ohtsu H 2006 The accelerating effect of histamine on the cutaneous wound-healing process through the action of basic fibroblast growth factor. Journal of Investigative Dermatology 126 1403-1409.

Pepper MS, Ferrara N, Orci L \& Montesano R 1992 Potent synergism between vascular endothelial growth factor and basic fibroblast growth factor in the induction of angiogenesis in vitro. Biochemical and Biophysical Research Communications 189 824-831.

Picton HM, Campbell BK \& Hunter MG 1999 Maintenance of oestradiol production and expression of cytochrome P450 aromatase enzyme mRNA in long-term serum-free cultures of pig granulosa cells. Journal of Reproduction and Fertility 115 67-77.

Presta M, Dell'Era P, Mitola S, Moroni E, Ronca R \& Rusnati M 2005 Fibroblast growth factor/fibroblast growth factor receptor system in angiogenesis. Cytokine and Growth Factor Reviews 16 159-178.

Redmer DA \& Reynolds LP 1996 Angiogenesis in the ovary. Reviews of Reproduction 1 182-192.

Reinmuth N, Liu W, Jung YD, Ahmad SA, Shaheen RM, Fan FAN, Bucana CD, McMahon G, Gallick GE \& Ellis LM 2001 Induction of VEGF in perivascular cells defines a potential paracrine mechanism for endothelial cell survival. FASEB Journal 15 1239-1241.

Reynolds LP \& Redmer DA 1998 Expression of the angiogenic factors, basic fibroblast growth factor and vascular endothelial growth factor, in the ovary. Journal of Animal Science 76 1671-1681.

Robinson RS, Nicklin LT, Hammond AJ, Schams D, Hunter MG \& Mann GE 2007 Fibroblast growth factor 2 is more dynamic than vascular endothelial growth factor A during the follicle-luteal transition in the cow. Biology of Reproduction 77 28-36.

Robinson RS, Hammond AJ, Mann GE \& Hunter MG 2008 A novel physiological culture system that mimics luteal angiogenesis. Reproduction 135 405-413.

Shores EM \& Hunter MG 2000 The influence of blood cells and PDGF on porcine theca cell function in vitro. Animal Reproduction Science $\mathbf{6 4}$ 247-258.

Sleer LS \& Taylor CC 2007a Cell-type localization of platelet-derived growth factors and receptors in the postnatal rat ovary and follicle. Biology of Reproduction 76 379-390.
Sleer LS \& Taylor CC 2007 b Platelet-derived growth factors and receptors in the rat corpus luteum: localization and identification of an effect on luteogenesis. Biology of Reproduction 76 391-400.

Strawn LM, McMahon G, App H, Schreck R, Kuchler WR, Longhi MP, Hui TH, Tang C, Levitzki A, Gazit A et al. 1996 Flk-1 as a target for tumor growth inhibition. Cancer Research 56 3540-3545.

Sugiura K, Su Y-Q, Diaz FJ, Pangas SA, Sharma S, Wigglesworth K, O'Brien MJ, Matzuk MM, Shimasaki S \& Eppig JJ 2007 Oocyte-derived BMP15 and FGFs cooperate to promote glycolysis in cumulus cells. Development 134 2593-2603.

Taylor CC 2000 Platelet-derived growth factor activates porcine thecal cell phosphatidylinositol-3-kinase-Akt/PKB and Ras-extracellular signalregulated kinase-1/2 kinase signaling pathways via the platelet-derived growth factor- $\beta$ receptor. Endocrinology 141 1545-1553.

Tennant JR 1964 Evaluation of the trypan blue technique for determination of cell viability. Transplantation 2 685-694.

Wang Y, Chang J, Chen KD, Li S, Li JY, Wu C \& Chien S 2007 Selective adapter recruitment and differential signaling networks by VEGF vs shear stress. PNAS 104 8875-8879.

Yamashita H, Kamada D, Shirasuna K, Matsui M, Shimizu T, Kida K, Berisha B, Schams D \& Miyamoto A 2008 Effect of local neutralization of basic fibroblast growth factor or vascular endothelial growth factor by a specific antibody on the development of the corpus luteum in the cow. Molecular Reproduction and Development 75 1449-1456.

Zheng J, Redmer DA \& Reynolds LP 1993 Vascular development and heparin-binding growth factors in the bovine corpus luteum at several stages of the estrous cycle. Biology of Reproduction 49 1177-1189.

Zimmermann RC, Hartman T, Bohlen P, Sauer MV \& Kitajewski J 2001 Preovulatory treatment of mice with anti-VEGF receptor 2 antibody inhibits angiogenesis in corpora lutea. Microvascular Research 62 $15-25$.

Received 30 January 2009

First decision 23 March 2009

Revised manuscript received 3 June 2009

Accepted 19 June 2009 